\title{
Critical points in ethylcellulose matrices: Influence of the polymer, drug and filler properties
}

\author{
CELIA CIFUENTES ${ }^{1}$ \\ ÁNGELA AGUILAR-DE-LEYVA ${ }^{1}$ \\ ALI R. RAJABI-SIAHBOOMI ${ }^{2}$ \\ ISIDORO CARABALLO ${ }^{1}$ \\ ${ }^{1}$ Department of Pharmacy \\ and Pharmaceutical Technology \\ University of Seville, 41012 Seville \\ Spain \\ ${ }^{2}$ Colorcon Inc. Global Headquarters \\ Harleysville, PA 19438, USA
}

\begin{abstract}
Percolation theory has been applied to study the drug release behaviour in multicomponent inert matrices containing ethylcellulose as a matrix forming polymer. Global influence of major formulation factors such as polymer viscosity, polymer particle size, drug and filler solubility and porosity of the tablets in drug release kinetics has been studied for the first time. Batches containing three viscosity grades of Ethocel $^{\mathrm{TM}}$, microcrystalline cellulose (MCC) and lactose as fillers, a lubricant and flow aid mixture and three drugs with different solubility have been manufactured. For some batches, compression pressure was varied in order to obtain matrices with five levels of initial porosity. The behaviour of inert matrices was explained based on the percolation ranges of the main components of the formulation. The effect of the porosity percolation threshold was observed and the existence of a tricoherent drug-polymer-filler system is hypothesized.
\end{abstract}

Keywords: inert matrices, critical points, percolation theory, sustained release

Due to their simple and low-cost manufacturing process, matrix tablets are pharmaceutical dosage forms most widely used for the formulation of oral controlled release of drugs (1). These systems involve dispersion of one or more drugs in a support structure, which in the majority of the cases is of polymeric nature.

Inert matrices are systems that consist of a polymeric porous solid network, which is insoluble and indigestible in the gastrointestinal tract (2). Drug release from these dosage forms occurs by drug diffusion through the pores of the matrices, including the initial pores and the pores that appear when the drug or soluble excipients have been dissolved (3).

Ethylcellulose is a water insoluble polymer that has been used in the manufacturing of different solid oral dosage forms. It is used in the preparation of microcapsules and microspheres, as a barrier membrane in reservoirs, and as inert matrix-former for oral

\footnotetext{
* Correspondence; e-mail: tinixcifo@gmail.com
} 
sustained release dosage forms. The properties of ethylcellulose used as an excipient for obtaining tablets by direct compression has been extensively studied (4-6).

Percolation theory studies the critical points of systems. These critical points correspond to the critical occupation probability in a mathematical lattice model. Nevertheless, when the concepts of percolation theory are applied to pharmaceutical tablets, these critical points correspond to the critical concentration of one or more components of the system, including tablet porosity (7). At these points, one component of the system experiences a geometrical phase transition and starts to spread over the whole system, having much greater influence on the properties of the entire system (8). Thus, according to the percolation theory, sudden changes are expected to happen in the properties of the system when a component reaches its percolation threshold.

A key concept of the percolation theory is the concept of clusters. A cluster is defined as a group of neighbouring particles of the same component. It is considered coherent or percolating when the group of neighbouring particles extends from one side to the other sides of the system, i.e., it percolates through the entire system. Otherwise, the cluster is called finite or isolated $(7,9)$.

This theory was first applied to the pharmaceutical sciences by Leuenberger and co-workers in 1987 (9-14). Since then, concepts of the percolation theory have been applied to the study and design of different types of sustained release matrix systems, starting with inert matrices $(3,11-12)$. According to the percolation theory, an inert matrix must be formulated above the drug percolation threshold (the sum of the initial porosity of the system plus the volumetric fraction of the drug must percolate through the system, since in inert matrices the pores allow water uptake and drug release). Otherwise, a fraction of the drug would remain in the matrix surrounded by the insoluble excipient (11-12).

On the other hand, the polymer must also be above its percolation threshold, where polymer networks percolate across the matrix system. In this way, disintegration of the matrix during the release process is avoided and the matrix controls drug release (15-16). Most of these percolation thresholds are around 30-35\% (V/V) (17). As previously reported, an understanding of the critical points of the formulation as well as their relationship with the main factors affecting the behaviour of the system will result in a more robust formulation and faster industrial development.

Previous works have estimated the percolation thresholds of different drugs such as morphine hydrochloride (16), naltrexone hydrochloride (15) and dextromethorphan hydrobromide (18) and excipients like ethylcellulose (19) or acrylic polymers (20) in binary and ternary inert matrices.

In the present work, typical multi-component controlled release matrix tablets have been studied using ethylcellulose as the matrix forming polymer, two common fillers of different solubility (microcrystalline cellulose and lactose), a lubricant and flow aid mixture and three drugs with different solubility (verapamil hydrochloride, carbamazepine and sodium diclofenac). The presence of these components introduces a higher level of complexity to the study of the behaviour of these systems with respect to the binary matrices previously reported in the literature.

The aim of this study is to explain the release behaviour of the studied multicomponent ethylcellulose matrices, based on percolation ranges of the main components of the formulations, i.e., drug, filler and polymer, to provide a general explanation of the kinetic behaviour of the prepared matrices. 
EXPERIMENTAL

\section{Materials}

The following materials were used for the preparation of matrix tablets: Ethocel ${ }^{\mathrm{TM}} 7$ FP (particle size range 5-15 $\mu \mathrm{m}$ ), Ethocel ${ }^{\mathrm{TM}} 10 \mathrm{FP}$ (particle size range 3-15 $\mu \mathrm{m}$ ), Ethocel ${ }^{\mathrm{TM}}$ $100 \mathrm{FP}$ (particle size range 30-60 $\mu \mathrm{m}$ ) (Colorcon Ltd.,UK) as matrix forming polymers, verapamil hydrochloride (mean particle size $120.5 \pm 45.2 \mu \mathrm{m}$ ) (Recordatti, Italy), carbamazepine (mean particle size $138.9 \pm 47.8 \mu \mathrm{m}$ ) (Fagron, Spain) and sodium diclofenac (mean particle size $212.4 \pm 75.9 \mu \mathrm{m}$ ) (Fagron, Spain) as model drugs with different solubility. Solubility values as well as the true density of the drugs were taken from the literature: verapamile $\left(45.4 \mathrm{~g} \mathrm{~L}^{-1}\right.$ and $\left.1.160 \mathrm{~g} \mathrm{~cm}^{-3}\right)$; carbamazepine $\left(0.12 \mathrm{~g} \mathrm{~L}^{-1}\right.$ and $\left.1.330 \mathrm{~g} \mathrm{~cm}^{-3}\right)$ and sodium diclofenac (20.4 $\mathrm{g} \mathrm{L}^{-1}$ and $\left.1.022 \mathrm{~g} \mathrm{~cm}^{-3}\right)$.

Fast Flo lactose (Foremost, USA) and microcrystalline cellulose (MCC) (AVICEL PH 102), (FMC BioPolymer, Ireland) were used as fillers while magnesium stearate (Fagron, Spain) and colloidal silicon dioxide (AEROSIL 200) (Degussa, Germany) were employed as lubricants and flow aid, respectively.

\section{Tablet preparation}

Twenty batches of inert matrices containing $90 \mathrm{mg}$ of verapamil hydrochloride, carbamazepine or diclofenac and an initial porosity between 0 and $5 \%$ were prepared. Table I shows the composition of the studied formulations. Ten more batches containing $90 \mathrm{mg}$ of carbamazepine and $40 \%(\mathrm{~m} / \mathrm{m})$ of ethylcellulose $\left(5\right.$ batches of Ethocel ${ }^{\mathrm{TM}} 7 \mathrm{FP}$ and 5 batches of Ethocel ${ }^{\mathrm{TM}} 10 \mathrm{FP}$ ) were prepared with 5 different porosities, ranging from 0 to $25 \%$ $(V / V)$. Table I shows the composition of these formulations as well.

All materials, with the exception of magnesium stearate, were blended for $10 \mathrm{minu}-$ tes in a Turbula mixer (Willy A. Bachofen, Switzerland). Magnesium stearate was added and blended for an additional 2 minutes. A standard eccentric tablet machine (Bonals A-300, Spain) equipped with $9 \mathrm{~mm}$ flat punches was used to compress the mixtures in order to obtain tablets with a target weight of $300 \mathrm{mg}$.

The powder blends were weighed and placed manually into the die of the compression machine (60 tablets per lot). The position of the upper punch was adjusted according to the initial porosity and crushing force of the tablets.

\section{Tablet characterization}

The mass of 10 tablets corresponding to each lot was measured using an electronic balance (Sartorius CP 2245). Thickness and diameter of 10 tablets of each lot were measured using a 25-mm digital micrometer (Comecta, SA).

The volume of 10 tablets from each batch was calculated according to the following Eq. (1):

$$
V=\pi H(D / 2)^{2}
$$

where $V$ is the tablet volume. $H$ and $D$ are tablet thickness and diameter, respectively. 
C. Cifuentes et al.: Critical points in ethylcellulose matrices: Influence of the polymer, drug and filler properties, Acta Pharm. 63 (2013) 115-129.

Table I. Composition (in percentage) of the different formulations prepared

\begin{tabular}{|c|c|c|c|c|c|c|c|c|c|c|}
\hline & $\begin{array}{c}\text { Carba- } \\
\text { mazepine }\end{array}$ & $\begin{array}{l}\text { Diclo- } \\
\text { fenac }\end{array}$ & $\begin{array}{l}\text { Vera- } \\
\text { pamil }\end{array}$ & $\begin{array}{c}\text { Ethocel } \\
7 \mathrm{FP}\end{array}$ & $\begin{array}{c}\text { Ethocel } \\
10 \mathrm{FP}\end{array}$ & $\begin{array}{l}\text { Ethocel } \\
100 \mathrm{FP}\end{array}$ & MCC & Lactose & $\mathrm{SiO}_{2}$ & $\begin{array}{c}\mathrm{Mg}- \\
\text {-stearate }\end{array}$ \\
\hline $\mathrm{FP} \mathrm{V1}{ }^{\mathrm{a}}$ & & & 30.0 & 10.0 & & & 59.0 & & 0.5 & 0.5 \\
\hline $\mathrm{FP} \mathrm{V} 2^{\mathrm{a}}$ & & & 30.0 & 20.0 & & & 49.0 & & 0.5 & 0.5 \\
\hline $\mathrm{FP} \mathrm{V3}{ }^{\mathrm{a}}$ & & & 30.0 & 30.0 & & & 39.0 & & 0.5 & 0.5 \\
\hline $\mathrm{FP} V 4^{\mathrm{a}}$ & & & 30.0 & 40.0 & & & 29.0 & & 0.5 & 0.5 \\
\hline $\mathrm{FP} V 5^{\mathrm{a}}$ & & & 30.0 & 50.0 & & & 19.0 & & 0.5 & 0.5 \\
\hline $\mathrm{FP} \mathrm{V} 6^{\mathrm{a}}$ & & & 30.0 & & & 10.0 & 59.0 & & 0.5 & 0.5 \\
\hline $\mathrm{FP} V 7^{\mathrm{a}}$ & & & 30.0 & & & 20.0 & 49.0 & & 0.5 & 0.5 \\
\hline FP V8 ${ }^{a}$ & & & 30.0 & & & 30.0 & 39.0 & & 0.5 & 0.5 \\
\hline FP V9a & & & 30.0 & & & 40.0 & 29.0 & & 0.5 & 0.5 \\
\hline $\mathrm{FP} V 10^{\mathrm{a}}$ & & & 30.0 & & & 50.0 & 19.0 & & 0.5 & 0.5 \\
\hline $\mathrm{FP} \mathrm{C} 1^{\mathrm{a}}$ & 30.0 & & & 10.0 & & & & 59.0 & 0.5 & 0.5 \\
\hline $\mathrm{FP} \mathrm{C} 2^{\mathrm{a}}$ & 30.0 & & & 20.0 & & & & 49.0 & 0.5 & 0.5 \\
\hline $\mathrm{FP} \mathrm{C} 3^{\mathrm{a}}$ & 30.0 & & & 30.0 & & & & 39.0 & 0.5 & 0.5 \\
\hline $\mathrm{FP} \mathrm{C} 4^{\mathrm{a}}$ & 30.0 & & & 40.0 & & & & 29.0 & 0.5 & 0.5 \\
\hline $\mathrm{FP} \mathrm{C5} 5^{\mathrm{a}}$ & 30.0 & & & 50.0 & & & & 19.0 & 0.5 & 0.5 \\
\hline $\mathrm{FP} D 1^{\mathrm{a}}$ & & 30.0 & & 10.0 & & & 59.0 & & 0.5 & 0.5 \\
\hline $\mathrm{FP} \mathrm{D} 2^{\mathrm{a}}$ & & 30.0 & & 20.0 & & & 49.0 & & 0.5 & 0.5 \\
\hline $\mathrm{FP} \mathrm{D} 3^{\mathrm{a}}$ & & 30.0 & & 30.0 & & & 39.0 & & 0.5 & 0.5 \\
\hline $\mathrm{FP} \mathrm{D} 4^{\mathrm{a}}$ & & 30.0 & & 40.0 & & & 29.0 & & 0.5 & 0.5 \\
\hline FP D5 ${ }^{a}$ & & 30.0 & & 50.0 & & & 19.0 & & 0.5 & 0.5 \\
\hline $7 \mathrm{FP} \mathrm{CA}{ }^{\mathrm{a}}$ & 30.0 & & & 40.0 & & & & 29.0 & 0.5 & 0.5 \\
\hline 7FP CB ${ }^{b}$ & 30.0 & & & 40.0 & & & & 29.0 & 0.5 & 0.5 \\
\hline $7 \mathrm{FP} \mathrm{CC}^{\mathrm{c}}$ & 30.0 & & & 40.0 & & & & 29.0 & 0.5 & 0.5 \\
\hline $7 \mathrm{FP} \mathrm{CD}^{\mathrm{d}}$ & 30.0 & & & 40.0 & & & & 29.0 & 0.5 & 0.5 \\
\hline $7 \mathrm{FP} \mathrm{CE}^{\mathrm{e}}$ & 30.0 & & & 40.0 & & & & 29.0 & 0.5 & 0.5 \\
\hline $10 \mathrm{FP} \mathrm{CA}^{\mathrm{a}}$ & 30.0 & & & & 40.0 & & & 29.0 & 0.5 & 0.5 \\
\hline $10 \mathrm{FP} \mathrm{CB}^{\mathrm{b}}$ & 30.0 & & & & 40.0 & & & 29.0 & 0.5 & 0.5 \\
\hline $10 \mathrm{FP} \mathrm{CC}^{\mathrm{c}}$ & 30.0 & & & & 40.0 & & & 29.0 & 0.5 & 0.5 \\
\hline $10 F P C^{d}$ & 30.0 & & & & 40.0 & & & 29.0 & 0.5 & 0.5 \\
\hline $10 \mathrm{FP} \mathrm{CE}^{\mathrm{e}}$ & 30.0 & & & & 40.0 & & & 29.0 & 0.5 & 0.5 \\
\hline
\end{tabular}

a Initial porosity between 0 and $5 \%(V / V)$.

b Initial porosity between 5 and $10 \%(\mathrm{~V} / \mathrm{V})$.

c Initial porosity between 10 and $15 \%(V / V)$.

d Initial porosity between 15 and $20 \%(V / V)$.

e Initial porosity between 20 and $25 \%(V / V)$. 
The initial porosity $\left(\varepsilon_{0}\right)$ was determined using known volume and weight values according to the following Eq. (2):

$$
\varepsilon_{0}=\left(V_{\text {real }}-V_{\text {theor }}\right) / V_{\text {real }}
$$

where $V_{\text {real }}$ is the volume of the tablet and $V_{\text {theor }}$ is the theoretical volume of the tablet, determined as the sum of volumes of individual components (obtained dividing the mass of each component by its real density).

Friability was determined for 20 tablets per lot using a friability tester Erweka TA (Germany) according to USP 26 (21).

Crushing forces of the tablets were determined using 10 tablets per lot, with a crushing strength tester Sotax HT1 (Sotax, Switzerland).

\section{Drug release}

Dissolution studies were performed using the paddle method in a USP dissolution apparatus Sotax AT7 smart (Sotax) for 6 tablets from each batch. $900 \mathrm{~mL}$ of distilled water at $37 \pm 0.5^{\circ} \mathrm{C}$ was used as dissolution medium. The stirring speed was fixed at $50 \mathrm{rpm}$ for verapamil hydrochloride and sodium diclofenac and at $100 \mathrm{rpm}$ for carbamazepine. Samples of $5 \mathrm{~mL}$ were withdrawn at $0.25,0.5,1.0,1.5,2,3,6$ and $8 \mathrm{~h}$. The percentage of drug released was measured using a UV/VIS spectrophotometer Agilent 8453 (USA) at $276 \mathrm{~nm}$ for sodium diclofenac, $278 \mathrm{~nm}$ for verapamil hydrochloride and $284 \mathrm{~nm}$ for carbamazepine.

Drug release data obtained for extended release matrices were fitted into the following equations: Eq. (3) (zero-order model), Eq. (4) proposed by Higuchi (22), Eq. (5) proposed by Korsmeyer et al. (23) and Eq. (6) proposed by Peppas and Sahlin (24).

$$
\begin{gathered}
Q=k_{0} t \\
Q=b \sqrt{t} \\
Q=k_{k} t^{n} \\
Q=k_{d} t^{m}+k_{r} t^{2 m}
\end{gathered}
$$

where $Q$ is the quantity of drug released at time $t, k_{0}$ is the zero order release rate constant in equation $3, b$ is the Higuchi release rate constant in equation $4, k_{\mathrm{k}}$ is the Korsmeyer kinetic constant in equation $5, t$ is the release time, $n$ is the Korsmeyer time exponent that depends on the release mechanism and on the shape of the matrix tested (25), $k_{\mathrm{d}}$ and $k_{\mathrm{r}}$ are the diffusion and relaxation rate constants, respectively, and $m$ is the purely Fickian diffusion exponent for a device of any geometrical shape exhibiting controlled release. 
Optimum values for the parameters included in each equation were determined by linear or nonlinear least-squares fitting methods using the SPSS 14.0 software. The determination coefficient $\left(R^{2}\right)$ was used to test the applicability of release models.

Results of the dissolution studies were employed to estimate the percolation threshold of the different components of the formulations. Phase transition is related to the presence of the percolation threshold of one component of the formulation, and normally produces a significant change in release profiles $(11,26)$.

\section{RESULTS AND DISCUSSION}

\section{Tablet characterization}

Results on the tablet diameter and thickness were used to determine the apparent volume of tablets. The weight and density of the different components of tablets were employed to calculate the volume fractions corresponding to each component and the initial porosity of the tablets manufactured. As an example, Table II shows the results (including the crushing strength and tablet friability data) for batches FP C1 to FP C5 (containing carbamazepine and Ethocel ${ }^{\mathrm{TM}} 7 \mathrm{FP}$ ). As it can be seen, high hardness values were obtained. These values are considered adequate for obtaining controlled release systems, especially inert matrix systems that must not erode during the drug release process. On the other hand, friability values are adequate, with the exception of batch FP C1, containing only $10 \%$ of ethylcellulose. This fact seems to indicate that the plasticity of ethylcellulose improves the cohesion strength of the tablet.

\section{Drug release profiles and release kinetics}

Thirty batches of tablets were prepared employing three different drugs, two different fillers, a lubricant mixture and three different viscosity grades of Ethocel ${ }^{\mathrm{TM}}$. Table I shows the composition and porosity level of each formulation. Results of dissolution studies are discussed below.

\section{Estimation of the ethylcellulose percolation threshold}

Release profiles as well as kinetic parameters of the different batches were employed to estimate the excipient percolation threshold of each formulation. A sudden change in kinetic parameters indicates a change in the release behaviour that could be indicative of a phase transition due to the presence of the percolation threshold of ethylcellulose.

Considering the release profiles of the different batches, the percolation threshold of the matrix forming polymer can be situated between 20 and $30 \%(\mathrm{~m} / \mathrm{m})$ for the matrices containing sodium diclofenac (batches FP D, Fig. 1b). Changes in kinetic parameters shown in Table III, including $b$ (Higuchi equation) ranging from 7.2778 to $5.8827 \mathrm{~min}^{-0.5}, k_{0}$ (zero order equation) ranging from 0.6696 to $0.4867 \mathrm{~min}^{-1}, k_{\mathrm{k}}$ (Korsmeyer model) ranging from 12.219 to $4.9828 \mathrm{~min}^{-n}$ and $k_{\mathrm{d}}$ and $k_{\mathrm{r}}$ (Peppas and Sahlin model) ranging from 15.050 to $10.586 \mathrm{~min}^{-0.425}$ and -0.555 to $-0.253 \mathrm{~min}^{-0.850}$, respectively, confirm the critical point observed in the release profiles. The behaviour of the Ethocel ${ }^{\mathrm{TM}} 100$ FP matrices (Fig. 2b 
C. Cifuentes et al.: Critical points in ethylcellulose matrices: Influence of the polymer, drug and filler properties, Acta Pharm. 63 (2013) 115-129.

Table II. Formulation composition and physico-mechanical characteristics of carbamazepine and Ethocel 7 FP inert matrices

\begin{tabular}{|c|c|c|c|c|c|}
\hline & \multicolumn{5}{|c|}{ Batch } \\
\hline & FP C1 & FP C2 & FP C3 & FP C4 & FP C5 \\
\hline Mass $^{\mathrm{b}}(\mathrm{g})$ & $0.299 \pm 0.006^{a}$ & $0.298 \pm 0.005^{\mathrm{a}}$ & $0.298 \pm 0.005^{a}$ & $0.297 \pm 0.004^{a}$ & $0.297 \pm 0.006^{\mathrm{a}}$ \\
\hline $\operatorname{Drug}(m / m)$ & 0.30 & 0.30 & 0.30 & 0.30 & 0.30 \\
\hline Ethocel $^{*}(m / m)$ & 0.10 & 0.20 & 0.30 & 0.40 & 0.50 \\
\hline Lactose $(\mathrm{g})$ & 0.590 & 0.490 & 0.390 & 0.290 & 0.190 \\
\hline Mg-stearate (g) & 0.005 & 0.005 & 0.005 & 0.005 & 0.005 \\
\hline $\mathrm{SiO}_{2}(\mathrm{~g})$ & 0.005 & 0.005 & 0.005 & 0.005 & 0.005 \\
\hline Volume $\left(\mathrm{cm}^{3}\right)^{\mathrm{b}}$ & $0.215 \pm 0.027^{a}$ & $0.221 \pm 0.031^{\mathrm{a}}$ & $0.228 \pm 0.029^{a}$ & $0.234 \pm 0.028^{a}$ & $0.241 \pm 0.026^{\mathrm{a}}$ \\
\hline Total porosity $(\%)$ & 33.45 & 32.56 & 31.50 & 30.74 & 29.80 \\
\hline Initial porosity (\%) & 2.03 & 2.16 & 1.97 & 2.12 & 1.96 \\
\hline Carbamazepine $(\%, V / V)$ & 31.42 & 30.40 & 29.53 & 28.61 & 27.84 \\
\hline Ethocel $(\%, V / V)$ & 12.22 & 23.64 & 34.45 & 44.51 & 54.13 \\
\hline Lactose $(\%, V / V)$ & 53.37 & 42.88 & 33.15 & 23.89 & 15.23 \\
\hline Mg stearate $(\%, V / V)$ & 0.64 & 0.62 & 0.60 & 0.58 & 0.57 \\
\hline $\mathrm{SiO}_{2}(\%, V / V)$ & 0.32 & 0.31 & 0.30 & 0.29 & 0.28 \\
\hline dens. Carbamazepine & 1.330 & 1.330 & 1.330 & 1.330 & 1.330 \\
\hline dens. Ethocel & 1.140 & 1.140 & 1.140 & 1.140 & 1.140 \\
\hline dens. Lactose & 1.540 & 1.540 & 1.540 & 1.540 & 1.540 \\
\hline dens Mg-stearate & 1.092 & 1.092 & 1.092 & 1.092 & 1.092 \\
\hline dens. $\mathrm{SiO}_{2}$ & 2.200 & 2.200 & 2.200 & 2.200 & 2.200 \\
\hline Hardness $(\mathrm{N})^{\mathrm{c}}$ & $275 \pm 0.120^{\mathrm{a}}$ & $289 \pm 0.151^{\mathrm{a}}$ & $299 \pm 0.163^{a}$ & $281 \pm 0.132^{\mathrm{a}}$ & $270 \pm 0.137^{a}$ \\
\hline Friability $(\%)^{c}$ & 1.00 & 0.25 & 0.57 & 0.43 & 0.36 \\
\hline
\end{tabular}

a Standard error of the mean.

${ }^{\mathrm{b}} n=10,{ }^{\mathrm{c}} n=20$

and Table III) is also consistent with this assumption. On the other hand, in the matrices prepared with Ethocel ${ }^{\mathrm{TM}} 7 \mathrm{FP}$ and verapamil hydrochloride (Fig. 2a), no clear change in release profiles can be observed.

In the case of inert matrices containing carbamazepine and Ethocel ${ }^{\mathrm{TM}} 7 \mathrm{FP}$ (batches FP C), the lot FP C3 $\left(30 \%(\mathrm{~m} / \mathrm{m})\right.$ of Ethocel $\left.{ }^{\mathrm{TM}} 7 \mathrm{FP}\right)$ shows an anomalous behaviour (Fig. 1a). Therefore, the change in release behaviour attributable to the percolation of the polymer is observed between 20 and $40 \%(\mathrm{~m} / \mathrm{m})$ of Ethocel ${ }^{\mathrm{TM}} 7 \mathrm{FP}$. The results of kinetic studies confirm this statement, since a fast increase in kinetic constants can be observed when the concentration of ethylcellulose is lower than $40 \%(\mathrm{~m} / \mathrm{m})$, indicating lower control of drug release. These data support the results previously discussed in this section.

Therefore, as a general behaviour, these results suggest that the volumetric fraction of Ethocel, needed to obtain a percolating cluster of this polymer controlling the drug release, ranges from 21.7 (lot FP D2) to $31.8 \%(V / V)$ (lot FP V8). 

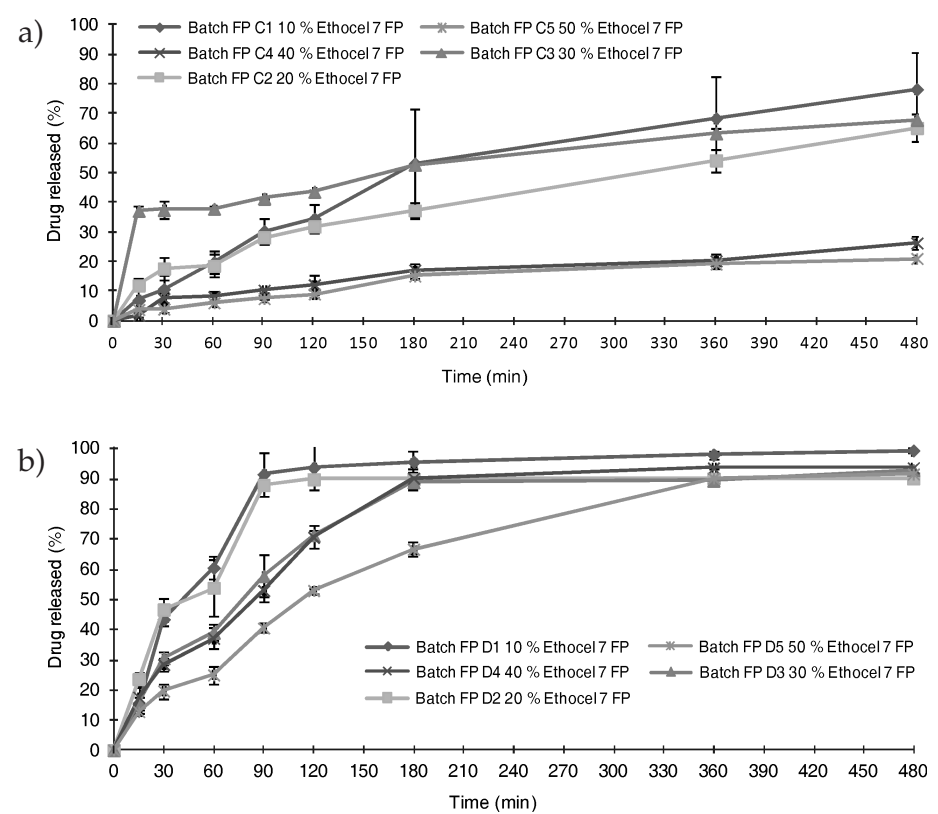

Fig. 1. Dissolution profiles of batches containing: a) carbamazepine and Ethocel $\left.{ }^{\mathrm{TM}} 7 \mathrm{FP}, \mathrm{b}\right)$ diclofenac sodium and Ethocel ${ }^{\mathrm{TM}} 7 \mathrm{FP}$.

This fact means that matrices containing less than $21.7 \%(V / V)$ Ethocel are expected to contain isolated clusters of this polymer, which will result in their lower ability to control drug release as well as higher probability of tablet disintegration during the drug release process.

\section{Effect of drug substances. Percolation of drug substances}

Although drug load was kept constant in weight, its volume fraction was not the same for the different drugs and batches, due to different densities of the substances employed as well as to the differences in volume of the tablets obtained.

\section{Sodium diclofenac}

Matrices containing sodium diclofenac showed the highest drug volume fraction, ranging from 33.5 to $37.5 \%(V / V)$ of drug. Addition of the initial porosity of the matrices to the drug volume fraction leads to a total porosity range from 35.1 to $39.5 \%(V / V)$.

This could explain why sodium diclofenac matrices show the fastest drug release rate, despite lower water solubility of sodium diclofenac compared to the solubility of verapamil hydrochloride (20.4 vs. $45.4 \mathrm{~g} \mathrm{~L}^{-1}$ ) (Figs. 1a,b and 2a).

Another argument that could explain faster release from sodium diclofenac matrices is the fact that diclofenac molecules have smaller volume than verapamil molecules, so that higher diffusivity could be expected. 
C. Cifuentes et al.: Critical points in ethylcellulose matrices: Influence of the polymer, drug and filler properties, Acta Pharm. 63 (2013) $115-129$.

Table III. Kinetic parameters of the formulations prepared maintaining constant the initial porosity

\begin{tabular}{ccccccccccc}
\hline & \multicolumn{4}{c}{ Higuchi } & \multicolumn{2}{c}{ Zero-order } & \multicolumn{3}{c}{ Korsmeyer } & \multicolumn{3}{c}{ Peppas and Sahlin } \\
\hline Batch & $b$ & $R^{2}$ & $k_{0}$ & $R^{2}$ & $k_{\mathrm{k}}$ & $n$ & $R^{2}$ & $k_{\mathrm{d}}$ & $k_{\mathrm{r}}$ & $R^{2}$ \\
\hline FP V1 & 6.4425 & 0.821 & 0.633 & 0.9365 & 0.9753 & 0.876 & 0.983 & 1.755 & 0.635 & 0.983 \\
FP V2 & 5.9139 & 0.9438 & 0.2116 & 0.8545 & 6.9033 & 0.349 & 0.957 & 4.448 & -0.027 & 0.982 \\
FP V3 & 3.3795 & 0.9787 & 0.1561 & 0.838 & 3.5715 & 0.549 & 0.969 & 4.857 & 0.105 & 0.975 \\
FP V4 & 2.745 & 0.9668 & 0.1072 & 0.8214 & 3.7024 & 0.529 & 0.922 & 6.674 & -0.141 & 0.965 \\
FP V5 & 1.931 & 0.978 & 0.0767 & 0.8588 & 5.8415 & 0.358 & 0.96 & 3.714 & -0.022 & 0.986 \\
FP V6 & 7.6104 & 0.9723 & 0.9445 & 0.9235 & 3.3973 & 0.708 & 0.943 & 12.911 & -0.378 & 0.976 \\
FP V7 & 5.109 & 0.9574 & 0.4291 & 0.9003 & 10.257 & 0.317 & 0.858 & 7.667 & -0.115 & 0.976 \\
FP V8 & 3.009 & 0.9434 & 0.1343 & 0.7547 & 7.3082 & 0.355 & 0.949 & 4.161 & 0.2500 & 0.961 \\
FP V9 & 3.2735 & 0.9542 & 0.2153 & 0.8191 & 8.5677 & 0.314 & 0.919 & 3.917 & 0.057 & 0.985 \\
FP V10 & 3.4972 & 0.9557 & 0.2251 & 0.7859 & 10.145 & 0.298 & 0.967 & 5.413 & -0.066 & 0.991 \\
FP C1 & 3.9112 & 0.9339 & 0.2863 & 0.9926 & 0.6914 & 0.827 & 0.993 & 3.585 & 0.1050 & 0.978 \\
FP C2 & 2.9056 & 0.9925 & 0.1191 & 0.9285 & 3.2413 & 0.472 & 0.969 & 2.987 & 0.0610 & 0.994 \\
FP C3 & 2.7911 & 0.8155 & 0.1194 & 0.599 & 24.928 & 0.123 & 0.701 & 6.250 & -0.160 & 0.92 \\
FP C4 & 1.1898 & 0.9747 & 0.0484 & 0.8972 & 0.5091 & 0.655 & 0.893 & 1.342 & 0.0180 & 0.974 \\
FP C5 & 1.0199 & 0.9719 & 0.0419 & 0.9153 & 0.6730 & 0.56 & 0.958 & 0.957 & 0.0270 & 0.973 \\
FP D1 & 7.9813 & 0.9235 & 0.7356 & 0.9716 & 7.1277 & 0.481 & 0.755 & 15.800 & -0.550 & 0.919 \\
FP D2 & 7.2778 & 0.9584 & 0.6696 & 0.9264 & 12.219 & 0.365 & 0.77 & 15.050 & -0.555 & 0.93 \\
FP D3 & 5.8827 & 0.9678 & 0.4867 & 0.9761 & 4.9828 & 0.511 & 0.913 & 10.586 & -0.253 & 0.943 \\
FP D4 & 5.3814 & 0.9833 & 0.4455 & 0.968 & 4.9381 & 0.512 & 0.934 & 10.08 & -0.211 & 0.939 \\
FP D5 & 4.6077 & 0.941 & 0.3046 & 0.9743 & 2.4645 & 0.609 & 0.974 & 5.82 & 0.035 & 0.97 \\
\hline
\end{tabular}

\section{Verapamil hydrochloride}

The drug volume fraction for verapamil hydrochloride matrices ranges between 30.3 and $34.3 \%(V / V)$. The total porosity, calculated adding the initial porosity of the matrices to the volumetric fraction of the drug, ranges from 33.1 to $38.1 \%(V / V)$.

Therefore, it can be expected that both sodium diclofenac and verapamil hydrochloride are situated above or very close to their percolation thresholds in the studied matrices (17). The obtained drug release profiles seem to confirm this hypothesis. Some of the batches released $100 \%$ of drug during the release assay and even for the lots containing higher amounts of polymer, the release rate shows significant values, suggesting that the drug was not encapsulated by the polymer.

\section{Carbamazepine}

In matrices containing drugs with slow dissolution kinetics, the presence of a fast dissolution filler will mask the percolation threshold of the drug. Therefore, due to the low dissolution rate of carbamazepine and to the presence of lactose, as soluble filler in 

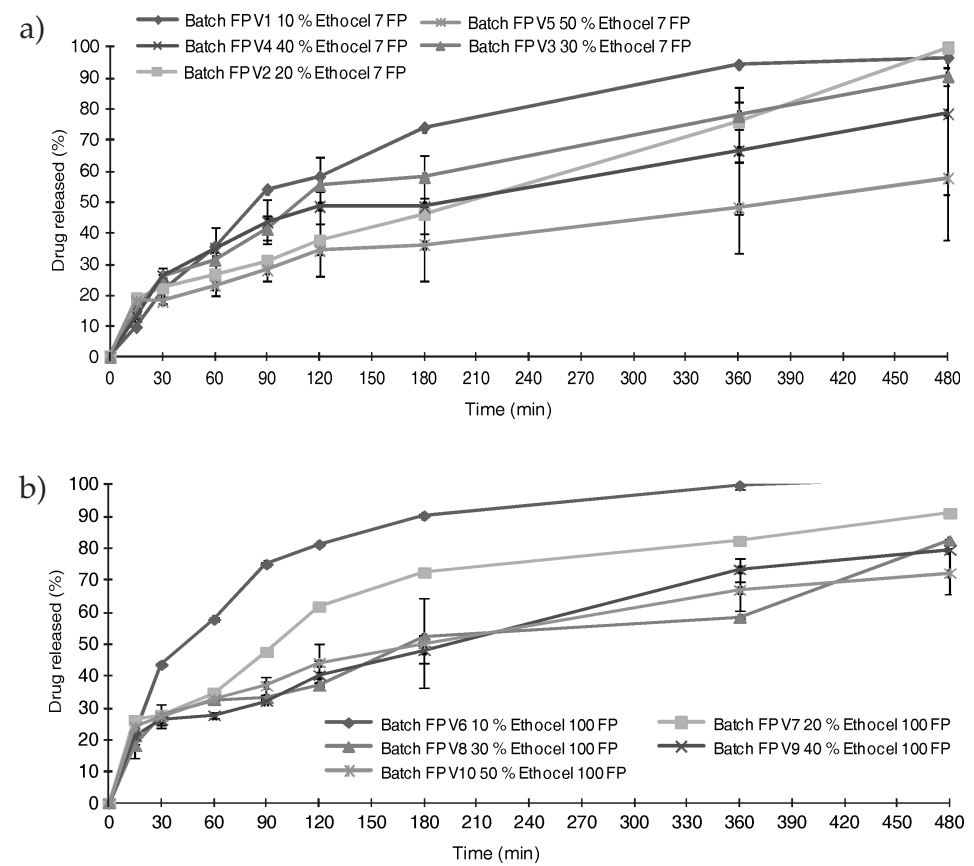

Fig. 2. Dissolution profiles of batches containing verapamil hydrochloride and Ethocel ${ }^{\mathrm{TM}}$ : a) 7 FP, b) $100 \mathrm{FP}$.

these matrices, the release profiles do not seem to be strongly affected by the percolation threshold of carbamazepine.

Fig. 1a shows a clear change in the release behaviour of lot FP C3 and lot FP C4. The volume fraction of the filler is 33.2 for lot FP C3 and $23.9 \%(V / V)$ for FP C4 (Table II). Therefore, this change can be attributed to the percolation of the filler in carbamazepine matrices. This means that the batches containing up to $23.9 \%(V / V)$ lactose $(40$ and $50 \%$ $(\mathrm{m} / \mathrm{m})$ of Ethocel) do not contain a percolating cluster of lactose, which is isolated by other components of the formulation, resulting in a slower release rate.

Batches with a content of lactose of $33.2 \%(\mathrm{~V} / \mathrm{V})$ or higher $(10$ to $30 \%(\mathrm{~m} / \mathrm{m})$ of Ethocel) contain a percolating cluster of lactose, i.e., in these tablets the soluble filler is dissolved as water ingresses into the matrix, acting as a channel former within the inert matrix through which the drug is released. In this way, the soluble filler exerts a strong influence on matrix properties, resulting in faster drug release (see lots FP C1, FP C2 and FP C3 in Fig. 1a).

Nevertheless, as it can also be observed in Fig. 1a, there is an unexpected behaviour of lot FP C3, showing a very fast initial drug release. This burst effect is clearly stronger than that exhibited by lots FP C1 and FP C2, though these lots contain a higher amount of lactose. As it can be observed in Table II, lot FP C3 contains $33.2 \%(V / V)$ of lactose, $34.5 \%(V / V)$ of Ethocel and $29.5 \%(V / V)$ of carbamazepine (plus $2 \%$ initial porosity). 
a) $100 \mathrm{~T} \rightarrow$ Batch 7FPCA 0-5\% Porosity $\rightarrow$ Batch 7FPCB 5-10\% Porosity

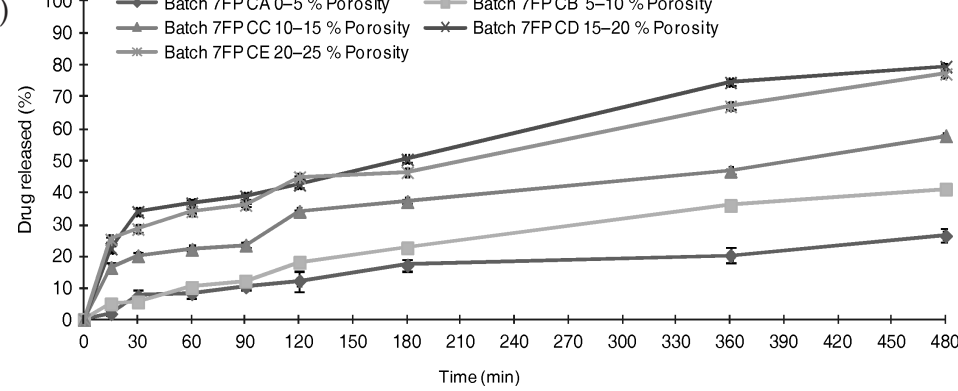

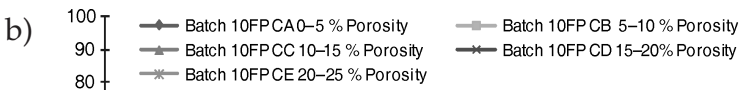

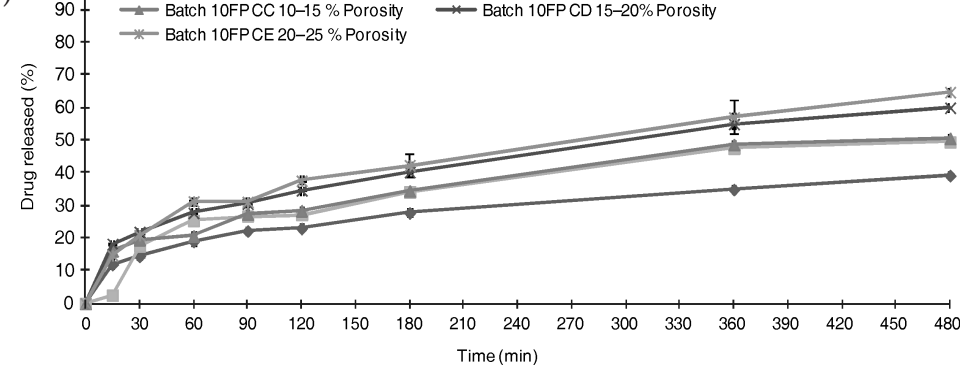

Fig. 3. Dissolution profiles of batches containing carbamazepine and $40 \%(\mathrm{~m} / \mathrm{m})$ of Ethocel ${ }^{\mathrm{TM}}$ : a) 7 FP, b) 10 FP.

Therefore, the three main components of this matrix: the poorly soluble drug, the insoluble polymer and the freely water soluble filler are above or very close to $30 \%(\mathrm{~V} / \mathrm{V})$. This is a special situation, which will allow all of these three components to percolate through the tablet. This structure, which can be called a tricoherent system, could be the reason for the anomalous behaviour found in the release assay of lot FP C3.

\section{Effect of polymer particle size and viscosity}

In order to study the effect of the polymer particle size and viscosity grade, matrix tablets containing verapamil hydrochloride, MCC and two polymers with different viscosity grades (Ethocel ${ }^{\mathrm{TM}} 7 \mathrm{FP}$ and Ethocel ${ }^{\mathrm{TM}} 100 \mathrm{FP}$ ) were prepared. These polymers have different particle sizes, Ethocel ${ }^{\mathrm{TM}} 7$ FP: $5-15 \mu \mathrm{m}$, and Ethocel ${ }^{\mathrm{TM}} 100 \mathrm{FP}: 30-60 \mu \mathrm{m}$ as well as different viscosity grades (7 and $100 \mathrm{mPa}$, respectively).

These two factors are expected to have opposite influence on drug release: on one hand, according to the percolation theory, a substance with a smaller particle size can spread over the system in a more effective way, exerting stronger influence on the system properties (27-29). In this sense, the matrices containing finer particles of ethylcellulose (Ethocel ${ }^{\mathrm{TM}} 7 \mathrm{FP}$ ) are expected to show slower drug release.

On the other hand, the higher viscosity of Ethocel ${ }^{\mathrm{TM}} 100 \mathrm{FP}$ would be expected to reduce the drug release rate, if release was through the polymer itself. 
Figs. $2 \mathrm{a}$ and $2 \mathrm{~b}$ show that the smaller particle size of the polymer exerted a stronger effect on the drug release rate than polymer viscosity, showing the matrices containing Ethocel $^{\mathrm{TM}} 100 \mathrm{FP}$ had a slightly faster release rate. This fact may be related to the compressibility of polymers, where lower viscosity grades undergo plastic deformation to a larger extent, thus leading to lower porosity.

\section{Effect of tablet porosity}

Five batches containing $30 \%$ of carbamazepine and $40 \%$ of Ethocel ${ }^{\mathrm{TM}} 7 \mathrm{FP}$ as well as 5 batches containing $30 \%$ of carbamazepine and $40 \%$ of Ethocel ${ }^{\mathrm{TM}} 10 \mathrm{FP}$ were prepared with 5 different porosity levels ranging from 0 to $25 \%$. Table I shows the composition and porosity levels of these batches.

Regardless of the type of polymer employed, it can be observed (Fig. 3) that the tablets with lower initial porosity $(0-5 \%(V / V)$ batches $C A)$ clearly show slower drug release. Changes in kinetic parameters are shown in Table IV. This could be attributed to
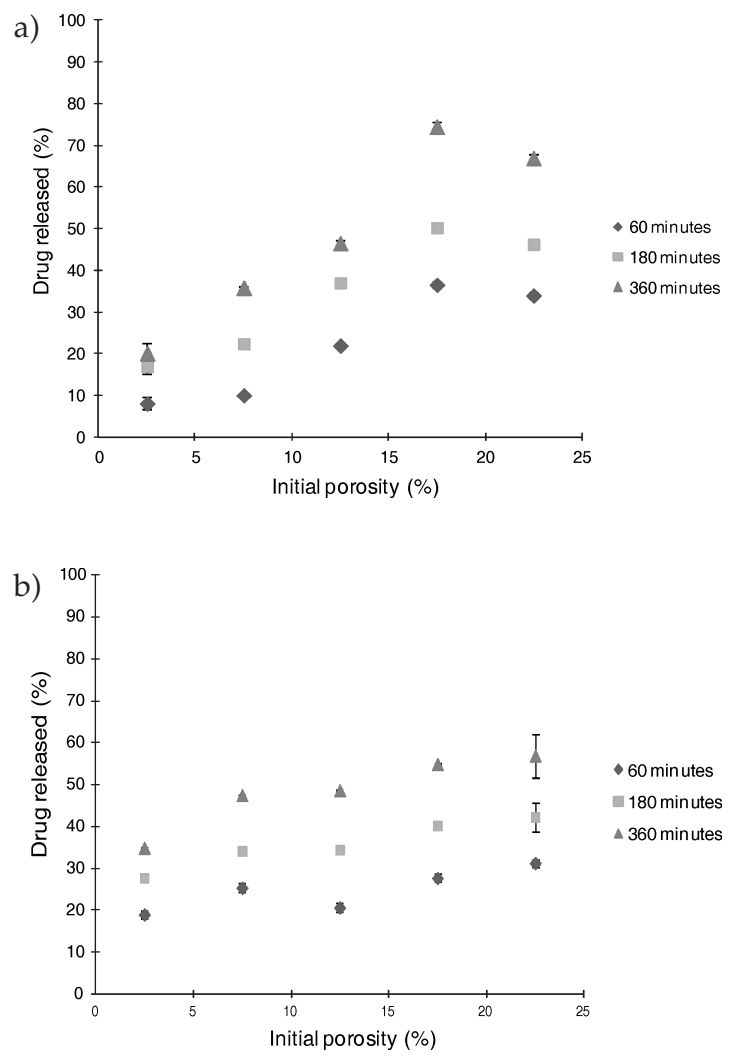

Fig. 4. Percentage of drug released vs. initial porosity of batches containing carbamazepine and Ethocel $^{\mathrm{TM}}$ : a) $7 \mathrm{FP}$, b) $10 \mathrm{FP}$. 
C. Cifuentes et al.: Critical points in ethylcellulose matrices: Influence of the polymer, drug and filler properties, Acta Pharm. 63 (2013) $115-129$.

Table IV. Kinetic parameters of the formulations prepared with five different levels of initial porosity

\begin{tabular}{lcccccccccc}
\hline & \multicolumn{3}{c}{ Higuchi } & \multicolumn{2}{c}{ Zero-order } & \multicolumn{3}{c}{ Korsmeyer } & \multicolumn{3}{c}{ Peppas and Sahlin } \\
\hline Batch & $b$ & $R^{2}$ & $k_{0}$ & $R^{2}$ & $k_{0}$ & $n$ & $R^{2}$ & $k_{0}$ & $k_{0}$ & $R^{2}$ \\
\hline 7FP CA & 1.1898 & 0.9747 & 0.0484 & 0.8972 & 0.5091 & 0.655 & 0.893 & 1.342 & 0.0180 & 0.974 \\
7FP CB & 1.983 & 0.9787 & 0.0834 & 0.9633 & 0.6757 & 0.667 & 0.981 & 1.197 & 0.0910 & 0.993 \\
7FP CC & 2.4097 & 0.9706 & 0.0963 & 0.8632 & 5.5622 & 0.363 & 0.943 & 3.463 & -0.008 & 0.976 \\
7FP CD & 3.4616 & 0.914 & 0.2158 & 0.7048 & 11.167 & 0.286 & 0.922 & 5.222 & -0.03 & 0.977 \\
7FP CE & 3.2769 & 0.9157 & 0.2044 & 0.7066 & 12.133 & 0.257 & 0.958 & 4.816 & -0.023 & 0.979 \\
10FP CA & 1.6793 & 0.9721 & 0.0652 & 0.8157 & 4.5539 & 0.347 & 0.997 & 3.119 & -0.047 & 0.996 \\
10FP CB & 2.3732 & 0.944 & 0.0927 & 0.802 & 0.9139 & 0.697 & 0.761 & 4.058 & -0.046 & 0.956 \\
10FP CC & 2.2218 & 0.9737 & 0.0877 & 0.8448 & 5.7892 & 0.346 & 0.964 & 3.582 & -0.03 & 0.985 \\
10FP CD & 2.5837 & 0.9804 & 0.1016 & 0.8442 & 6.6858 & 0.35 & 0.991 & 4.316 & -0.044 & 0.994 \\
10FP CE & 2.8382 & 0.9835 & 0.1118 & 0.8496 & 5.0329 & 0.415 & 0.981 & 4.626 & -0.041 & 0.994 \\
\hline
\end{tabular}

the fact that these matrices are below the percolation threshold of the soluble filler plus the initial porosity. The volumetric fraction of lactose for batch 7FP CA is $23.9 \%$ and the initial porosity is $0-5 \%$. Batch $10 \mathrm{FP}$ CA has a volumetric fraction of lactose of $23.8 \%$ $(V / V)$ and the initial porosity is also $0-5 \%(V / V)$. The volumetric fraction of the soluble filler and initial porosity is in both cases lower than $30 \%$ and therefore below the percolation threshold, which is expected to be between 30-35\% $(V / V)$.

On the other hand, lots prepared with more than $15 \%(V / V)$ of initial porosity (Batches $\mathrm{CD}$ and $\mathrm{CE}$ ) are expected to be above the percolation threshold of the filler plus initial porosity, showing a higher release rate.

Batches with an intermediate initial porosity compressed between 5-15\% ( V/V) (lots $\mathrm{CB}$ and $\mathrm{CC}$ ) are expected to be very close to the percolation threshold of the filler plus initial porosity. These batches show a behaviour intermediate between the previously depicted patterns.

The effect of porosity plus soluble filler was studied in the previous paragraph. Nevertheless, the effect of porosity can be also studied as an individual factor. It is well known from the percolation theory that, assuming a random distribution, the percolation of pores through a solid system shows a percolation threshold around $16 \%$ (28). Fig. 4 shows the behaviour of the percent of drug released at $1 \mathrm{~h}, 3 \mathrm{~h}$ and $6 \mathrm{~h}$ as a function of the initial tablet porosity.

As this figure shows, the obtained data are in good agreement with this hypothesis, showing an increase in the drug released for tablets containing more than $16 \%$ of initial porosity.

\section{CONCLUSIONS}

It has been shown in this paper that the release behaviour of the multicomponent inert matrices prepared can be explained according to the percolation ranges of their com- 
ponents. Studies of these percolation ranges are important in order to develop more robust controlled release formulations employing ethylcellulose as a matrix forming polymer. Concentration of the matrix forming polymer must be above its percolation threshold to guarantee the integrity of the matrix and to modulate drug release. Furthermore, the role of filler solubility and its percolation has been shown to be important factors affecting the release behaviour of the drug from inert matrices.

For these reasons, application of the percolation theory to the manufacturing of multicomponent inert matrices enables a science-based formulation that will lead to the concept of quality by design.

Acknowledgements. - The authors express their gratitude to Colorcon for funding this study and for the supply of Ethocel ${ }^{\mathrm{TM}}$. We also thank Recordatti for the supply of verapamil hydrochloride.

\section{REFERENCES}

1. M. Casas, C. Ferrero and M. R. Jiménez-Castellanos, Graft tapioca starch copolymers as novel excipients for controlled-release matrix tablets, Carbohydr. Polym. 80 (2010) 71-77; DOI: 10.1016/ j.carbpol.2009.10.065.

2. E. Costa, A. Arancibia and J. M. Aïache, Sistemas matriciales, Act. Farm. Bonaerense 23 (2004) 259-265.

3. I. Caraballo, M. Fernández-Arevalo, M. A. Holgado and A. M. Rabasco, Percolation theory: application to the study of the release behaviour from inert matrix systems, Int. J. Pharm. 96 (1993) 175-181; DOI: 10.1016/0378-5173(93)90225-5.

4. P. R. Katikaneni, S. M. Upadrashta, S. H. Neau and A. K. Mitra, Ethylcellulose matrix controlled release tablets of a water-soluble drug, Int. J. Pharm. 123 (1995) 119-125; DOI: 10.1016/0378$-5173(95) 00060-\mathrm{V}$.

5. S. I. Pather, I. Rusell, J. A. Syce and S. H. Neau, Sustained release theophylline tablets by direct compression: Part 1: formulation and in vitro testing, Int. J. Pharm. 164 (1998) 1-10; DOI: 10.1016/ S0378-5173(97)00348-7.

6. S. M. Upadrashta, P. R. Katikaneni, G. A. Hileman, S. H. Neau and C. E. Rowlings, Compressibility and compactibility properties of ethylcellulose, Int. J. Pharm. 112 (1994) 173-179; DOI: 10.1016/ 0378-5173(94)90427-8.

7. D. Stauffer and A. Aharony, Introduction to Percolation Theory, $2^{\text {nd }}$ ed., Taylor \& Francis, London 1992.

8. I. Caraballo, Factors affecting drug release from hydroxypropyl methyl cellulose matrix systems in the light of classical and percolation theories, Expert Opin. Drug Deliv. 7 (2010) 1291-1301; DOI: $10.1517 / 17425247.2010 .528199$.

9. H. Leuenberger, B. D. Rohera and C. Haas, Percolation theory - a novel approach to solid dosage form design, Int. J. Pharm. 38 (1987) 109-115; DOI: 10.1016/0378-5173(87)90105-0.

10. D. Blattner, M. Kolb and H. Leuenberger, Percolation theory and compactability of binary powder systems, Pharm. Res. 7 (1990) 113-117; DOI: 10.1023/ A:1015864415693.

11. J. D. Bonny and H. Leuenberger, Matrix type controlled release systems: I. Effect of percolation on drug dissolution kinetics, Pharm. Acta Helv. 66 (1991) 160-164.

12. J. D. Bonny and H. Leuenberger, Matrix type controlled release systems II. Percolation effects in non-swellable matrices, Pharm. Acta Helv. 68 (1993) 25-33; DOI: 10.1016/0031-6865(93)90005-Q.

13. L. E. Holman and H. Leuenberger, The relationship between solid fraction and mechanical properties of compacts - the percolation theory model approach, Int. J Pharm. 46 (1988) 35-44; DOI: DOI: 10.1016/0378-5173(88)90007-5. 
14. H. Leuenberger and R. Leu, Formation of a tablet: a site and bond percolation phenomenon, J. Pharm. Sci. 81 (1992) 976-982; DOI: 10.1002/jps.2600811004.

15. I. Caraballo, L. M. Melgoza, J. Alvarez-Fuentes, M. C. Soriano and A. M. Rabasco, Design of controlled release inert matrices of naltrexone hydrochloride based on percolation concepts, Int. J. Pharm. 181 (1999) 23-30; DOI: 10.1016/S0378-5173(98)00415-3.

16. L. M. Melgoza, I. Caraballo, J. Alvarez-Fuentes, M. Millan and A. M. Rabasco, Study of morphine hydrochloride percolation threshold in Eudragit ${ }^{\circledR}$ RS-PM matrices, Int. J. Pharm. 170 (1998) 169-177; DOI: 10.1016/S0378-5173(98)00135-5.

17. E. Castellanos-Gil, I. Caraballo and B. Bataille, Tablet Design, in Pharmaceutical Manufacturing Handbook: Production and Processes (Ed. S. C. Gad), Wiley InterScience, New Jersey 2008, pp. 977-1052.

18. L. M. Melgoza, A. M. Rabasco, H. Sandoval and I. Caraballo, Estimation of the percolation thresholds in dextromethorphan hydrobromide matrices, Eur. J. Pharm. Sci. 12 (2001) 453-459; DOI: 10.1016/S0928-0987(00)00193-7.

19. M. C. Soriano, I. Caraballo, M. Millan, R. T. Piñero, L. M. Melgoza and A. M. Rabasco, Influence of two different types of excipient on drug percolation threshold, Int. J. Pharm. 174 (1998) 63-69; DOI: 10.1016/S0378-5173(98)00255-5.

20. I. Caraballo, M. Fernandez-Arevalo, M. Millan, A.M.Rabasco and H. Leuenberger, Int. J. Pharm. 139 (1996) 177-186; DOI: 10.1016/0378-5173(96)04603-0.

21. United States Pharmacopoeia 26, National Formulary 21, USP Convention, Rockwille 2011.

22. T. Higuchi, Mechanism of sustained-action medication. Theoretical analysis of rate of release of solid drugs dispersed in solid matrices, J. Pharm. Sci. 52 (1963) 1145-1149.

23. R. W. Korsmeyer, R. Gurny, E. Doelker, P. Buri and N. A. Peppas, Mechanisms of solute release from porous hydrophilic polymers, Int. J. Pharm. 15 (1983) 25-35; DOI: 10.1016/0378-5173(83)90064-9.

24. N. A. Peppas and J. J. Sahlin, A simple equation for the description of solute release. III. Coupling of diffusion and relaxation, Int. J. Pharm. 57 (1989) 169-172; DOI: 10.1016/0378-5173(89)90306-2.

25. P. L. Ritger and N. A. Peppas, A simple equation for description of solute release I. Fickian and non-fickian release from non-swellable devices in the form of slabs, spheres, cylinders or discs, J. Control. Release 5 (1987) 23-36; DOI: 10.1016/0168-3659(87)90034-4.

26. I. Fuertes, A. Miranda, M. Millan and I. Caraballo, Estimation of the percolation thresholds in acyclovir hydrophilic matrix tablets, Eur. J. Pharm. Biopharm. 64 (2006) 336-342; DOI: 10.1016/ j.ejpb.2006.05.009.

27. I. Caraballo, M. Millán and A. M. Rabasco, Relationship between drug percolation threshold and particle size in matrix tablets, Pharm. Res. 13 (1996) 387-390; DOI: 10.1023/A:1016088424993.

28. M. Millán, I. Caraballo and A. M. Rabasco, The role of the drug/excipient particle size ratio in the percolation model for tablets, Pharm. Res. 15 (1998) 216-220; DOI: 10.1023/A:1011906416291.

29. I. Caraballo, M. Millan, A. Fini, L. Rodriguez and C. Cavallari, Percolation thresholds in ultrasound compacted tablets, J. Control. Release 69 (2000) 345-355; DOI: 10.1016/S0168-3659(00)00307-2. 